\title{
On the possible influence of radon and aerosol injection on the atmosphere and ionosphere before earthquakes
}

\author{
V. A. Liperovsky ${ }^{1}$, C.-V. Meister ${ }^{2}$, E.V. Liperovskaya ${ }^{1}$, V. F. Davidov ${ }^{3}$, and V. V. Bogdanov ${ }^{4}$ \\ ${ }^{1}$ Institute for Physics of the Earth, Moscow, Russia \\ ${ }^{2}$ High School and Science Programme Brandenburg/Potsdam, Project "Physics of Stellar and Planetary Atmospheres", \\ Germany \\ ${ }^{3}$ Moscow State University of Forrest, Mitishi, Russia \\ ${ }^{4}$ Institute of Cosmophysical Research and Radio Wave Propagation, Far Eastern Branch of RAS, P-Kamchatsky, Russia
}

Received: 15 June 2005 - Revised: 7 September 2005 - Accepted: 29 September 2005 - Published: 25 October 2005

Part of Special Issue "Seismic hazard evaluation, precursory phenomena and seismo electromagnetics"

\begin{abstract}
A model of the generation of pulses of local electric fields with characteristic time scales of 1-10 min is considered for atmospheric conditions above fracture regions of earthquakes. In the model, it is proposed that aerosols, increased ionization velocity and upstreaming air flows occur at night-time conditions. The pulses of local electric fields cause respective pulses of infrared emissions. But infrared emissions with time scales of 1-10 min were not observed up to now experimentally. The authors think, that the considered non-stationary field and radiation effects might be a new-type of applicable earthquake indicators and ask to perform special earth-based and satellite observations of the night-time atmosphere in seismoactive fracture regions.
\end{abstract}

\section{Introduction}

It is well known that aerosols modify the electric field of the atmosphere. In a series of works, it was suggested that, as a consequence of dispersion, friction of dust particles and attraction of small particles by dust ones, an electrically charged region occurs. Volcanic activity may also be a reason of electric field variations when large masses of ashes and other particles hurl out into the atmosphere. During periods of dust storms, the uncompensated charges may involve thunderstorms. In the papers by Kamra (1972), Kolokolov and Shalagina (1978), Al'perovich et al. (1986), and Pulinets et al. (2000), attention was paid to non-stationary electric processes connected with dust storms. Experiments showed that, in the atmosphere, deviations of the electric field from its mean value between $-10 \mathrm{kV} / \mathrm{m}$ and $15 \mathrm{kV} / \mathrm{m}$ occur $(\mathrm{Pu}$ linets et al., 2002).

Correspondence to: $\mathrm{C} .-\mathrm{V}$. Meister

(cvmeister@aip.de)
Besides the various electrical phenomena, there were also found different chemical compositions of aerosols in the near-earth atmosphere. In accordance with the observations by Kamra (1972) who analysed dust storms, the aerosols mainly consisted of clay-minerals, and they formed a negative volume charge at the earth's surface. On the other hand, if the aerosols were silicates, positive and negative polarities were observed at the surface. The sign of the electric field was found to depend on the altitude and the time evolution of the system of electrical charges.

At night when the temperature in the near-earth air is low and the relative humidity increases, above earth-fracture regions, it is very possible that water condensates at the aerosols. Then, the relatively large aerosol particles are mainly negatively charged while the charge of the smaller particles is overwhelmingly positive (Frenkel, 1949).

Further it is known that under special conditions, usual atmospheric clouds may become electro-gravitational generators. This phenomenon was already discussed in the works by Elster and Geitel (1913) and Geitel (1916) (see also Schumann, 1925; Wilson, 1929; Frenkel, 1949), which tried to explain the existence of a quasi-stationary electric field of the atmosphere. But also clouds in the atmosphere consisting of solid aerosols may be electro-gravitational generators. Such phenomena were investigated, for instance, with the scaling experiment "MASSA" (Al'perovich et al., 1986) and in a series of theoretical works (Trakhtengertz, 1989, 1992, 1994; Poljakov et al., 1990; Sorokin and Jashtshenko, 2000). In this connection, radioactive dust is of special importance, as it may considerably increase the atmospheric electric field. So, before earthquakes in regions of tectonic faults, pulses of electric fields up to $1000 \mathrm{~V} / \mathrm{m}$ were obtained (Vershinin et al., 1999). At the same time, essential amounts of the metallic aerosols $\mathrm{Cu}, \mathrm{Fe}, \mathrm{Ni}, \mathrm{Zn}, \mathrm{Pb}, \mathrm{Co}, \mathrm{Cr}$, and $\mathrm{Rn}$ occurred in the near-earth atmosphere. In the paper by Tronin et al. (2002) 


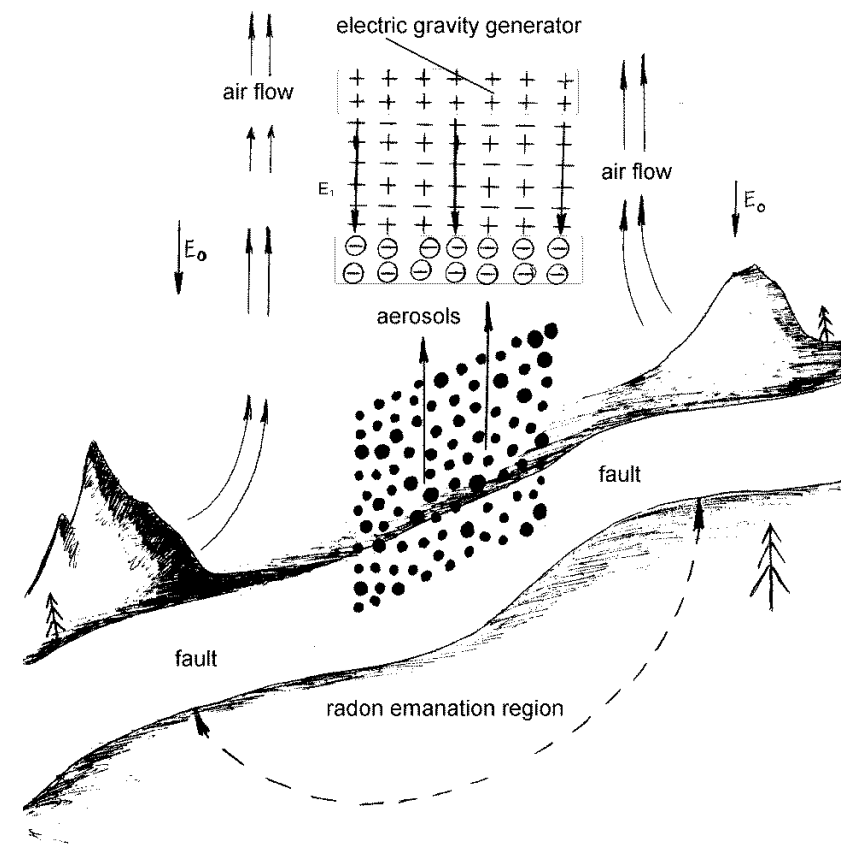

Fig. 1. The atmosphere above a fracture region some days before an earthquake.

it is noted that in China the dimensions of the fault regions where the atmospheric phenomena were registered were not larger than $700 \mathrm{~km}$ in length and $50 \mathrm{~km}$ in wideness.

A first physical model of the seismo-ionospheric links which, among other things, explains the generation of an anomalous electric field in the near-earth atmosphere before earthquakes, was developed by Pulinets et al. (2002). A later model by Pulinets and Boyarchuk (2004) considers already the appearance of ionization sources during a radon outflow out of the earth's core and the hydration process - the attraction of water molecules by the newly formed ions and ion clusters, which prevent the charged particles from recombination and make them quasi-stable. Generally, important points of formerly proposed models of seismo-ionospheric links are the outflow of metallic aerosols out off the earth's core in the fault regions, the ion-molecular reactions in the outflow regions of radioactive particles, and the turbulent diffusion (Boyarchuk et al., 1998). But non-stationary puls-like processes are not taken into account in the up-to-now known models.

In the present work, the non-stationary generation and destruction of the vertical electric field in the atmosphere above the fault region some days before earthquakes is studied on condition that in the atmosphere radon of lithospheric origin, aerosols and vertical wind flows occure (Fig. 1). The electric fields, for instance, may cause a sudden Joule heating of the electrons and ions, as well as pulses of infrared emissions, which are obtainable at night and analyzable in connection with attempts of earthquake prediction.

\section{Atmospheric model}

For simplicity, in the atmospheric model we propose, it is assumed that aerosol clouds of small dimensions are suddenly injected into near-earth, locally heated atmospheric layers and move with the air up to higher altitudes. The vertical dimension $L$ of the aerosol clouds is much smaller than the horizontal dimension. The characteristic time of the aerosol outflow $\tau_{s}$ is of the order of $10 \mathrm{~s}$, and thus it is much smaller than the characteristic time of the cloud evolution $\tau_{r}$ which amounts to some tens of minutes. Two types of aerosol partices are considered, small ones with a radius $r \leq 1 \mu \mathrm{m}$ and large ones with a radius $R \leq 10 \mu \mathrm{m}$. In analogy to the charges of droplets in thunderstorm clouds, the large aerosol particles are suggested to be negatively charged and the small particles have a positive charge (Frenkel, 1949; Shishkin, 1954). But the vertical velocity of the small particles is much smaller than the velocity of the large ones, which equals a few $\mathrm{cm} / \mathrm{s}$. As a consequence of the shift between the small and large particles, an "electro-gravitational aerosol generator" of local non-stationary electric fields and current mini-systems starts to work. As a result, pulses of the electric field occur in the atmosphere. It is suggested, that at an initial moment of time $t=0$, the above described aerosol cloud exists. Besides, it is assumed that the increase of the ionization intensity $q_{i}$ of the air is larger than the usually obtained value $q_{i}^{o} \approx 10 \mathrm{~cm}^{-3} \mathrm{~s}^{-1}$. A growth of the ionization intensity up to values of $q_{i} \approx\left(10^{2}-10^{4}\right) \mathrm{cm}^{-3} \mathrm{~s}^{-1}$ may be caused by the radon outflow in fault regions before earthquakes. This problem was discussed in a series of works (Virk and Singh, 1994; Heinke et al., 1995; Sorokin and Jashtshenko, 2000; Pulinets and Bojarchuk, 2004).

The analysis of the system of kinetic equations describing the ionization and recombination of the ions $n^{+}$and $n^{-}$, as well as the collisions of the ions with the aerosols determining the charges of the small $\left(N_{a}^{+}\right)$and large $\left(N_{a}^{-}\right)$aerosols (Smirnov, 1992; Pulinets et al., 2000) results into the following estimates: In case that the main process reducing the number of ions is the collisional recombination of the positive and negative ions,

$\frac{\partial n_{i}^{ \pm}}{\partial t}=q_{i}-\alpha n_{i}^{+} n_{i}^{-}, \quad n_{i}^{+}=n_{i}^{-}=n$,

under quasi-stationary conditions $n=\sqrt{q_{i} / \alpha}$, at $q_{i}^{o}=10 \mathrm{~cm}^{-3} \mathrm{~s}^{-1}$ and a recombination coefficient $\alpha=10^{-7} \mathrm{~cm}^{3-1}$, the ion concentration is $n_{o}=10^{4} \mathrm{~cm}^{-3}$, and the characteristic time of the formation of the quasistationary state equals $\tau_{o}=\left(\alpha q_{i}\right)^{-1 / 2} \approx 10^{3} \mathrm{~s}$.

If the charge transfer from the ions to the aerosols by collisons mainly limits the increase of the ion concentration,

$\frac{\partial n_{i}^{ \pm}}{\partial t}=q_{i}-n_{i}^{ \pm} \beta\left(N_{a}^{+}+N_{a}^{-}\right)$,

one has $n_{i}^{ \pm}=q_{i} /\left(\beta\left(N_{a}^{+}+N_{a}^{-}\right)\right)$for $\alpha n^{2} \ll n \beta\left(N_{a}^{+}+N_{a}^{-}\right)$(that means for $N_{a}^{+}>\sqrt{q_{i} \alpha} / \beta$ at $\left.N_{a}^{+} \gg N_{a}^{-}\right)$. Here $\beta$ is the recombination coefficient for the charge transfer from the 
ions to the aerosols. For instance, for $q_{i}=10^{2} \mathrm{~cm}^{-3} \mathrm{~s}^{-1}$, $\alpha=10^{-7} \mathrm{~cm}^{3} \mathrm{~s}^{-1}, \beta=2 \times 10^{-6} \mathrm{~cm}^{3} \mathrm{~s}^{-1}$, in accordance with (Smirnov 1992), it follows $N_{a}^{+}>1500 \mathrm{~cm}^{-3}$. Assuming $N_{a}^{+}=10^{4} \mathrm{~cm}^{-3}$, one has $n=0.5 \times 10^{4} \mathrm{~cm}^{-3}$. However, if there are only some aerosol particles and $N_{a}^{+} \leq \sqrt{q_{i} \alpha} / \beta$, one finds $n=3 \times 10^{4} \mathrm{~cm}^{-3}$ as $n=\sqrt{q_{i} / \alpha}$.

Thus, at constant intensity of ion formation, the aerosols cause a decrease of the ion concentration. Consequently, also the electrical conductivity decreases and the quasi-stationary electric field increases - as was already mentioned by Imjanitov and Shifrin (1962).

Using the model of a plane capacitor the charge of which increases thanks to the downward motion of negatively charged aerosols and decreases because of a compensating electric current, the electric field may be estimated by

$\frac{\partial E_{l}(t)}{\partial t}=\frac{1}{\varepsilon_{o}}\left(V_{-} Q^{-} N_{a}^{-}-\lambda_{o} \frac{n}{n_{o}} E_{l}(t)\right)$.

In case of a uniform downward motion of the negative aerosols, it follows

$\frac{4}{3} \pi R^{3} \rho_{a} g-6 \pi R \eta V_{-}-Q^{-} E_{l}=0$.

The positive volume charge in the aerosol cloud results from the positively charged small aerosols and from the positive as well as negative ions (Fig. 2).

From the last two equations, one gets the relation

$\frac{\partial E_{l}}{\partial t}=A-E_{l} B$

$A=\frac{2}{9} \frac{R^{2} \rho_{a} g Q^{-} N_{a}^{-}}{\eta \varepsilon_{o}}, \quad B=\frac{1}{\varepsilon_{o}}\left(\lambda_{o} \frac{n}{n_{o}}+\frac{\left(Q^{-}\right)^{2} N_{a}^{-}}{6 \pi \eta R}\right)$

for the maximum electric field of an elementary electrogravitational generator. Our estimates showed that the influence of the electric field on the velocity of the large aerosols is negligible in the near-earth atmosphere.

According to our analysis, the amplitude of the electric field pulses may be found by

$E_{l M}=\frac{2 R^{2} \rho_{a} N_{a}^{-} Q^{-} g n_{o}}{9 \eta \lambda_{o} n}$

For an undisturbed electrical conductivity at the earth's surface of $\lambda=10^{-14} \mathrm{Sm} \mathrm{m}^{-1}$, a concentration of the large aerosols $N_{a}^{-}=10^{9} \mathrm{~m}^{-3}$, an air viscosity $\eta=1.8 \times 10^{-5} \mathrm{~kg} \mathrm{~m}^{-1} \mathrm{~s}^{-1}$, an aerosol mass density $\rho_{a}=2.5 \times 10^{3} \mathrm{~kg} \mathrm{~m}^{-3}$ (Kondratjev and Poznjakov, 1981), a charge of the large aerosols $Q^{-}=2000 e(e-$ electron charge), $g=10 \mathrm{~ms}^{-2}, n_{o}=\sqrt{q_{i}^{o} / \alpha}=10^{4} \mathrm{~cm}^{-3}, n=0.5 \times 10^{4}$ $\mathrm{cm}^{-3}, n / n_{o}=0.5$, one obtaines $E_{l M}=2 \times 10^{6} \mathrm{~V} / \mathrm{m}$ (breakdown at $3 \times 10^{6} \mathrm{~V} / \mathrm{m}$ ).

The characteristic time scale of the electric field pulses $E_{l}$ is determined by the electrical conductivity $\lambda_{o} n / n_{o}$ and equals

$\tau_{r} \approx \frac{\varepsilon_{o} n_{o}}{\lambda_{o} n}=\frac{\varepsilon_{o} n_{o} \beta N_{a}^{+}}{\lambda_{o} q_{i}}$

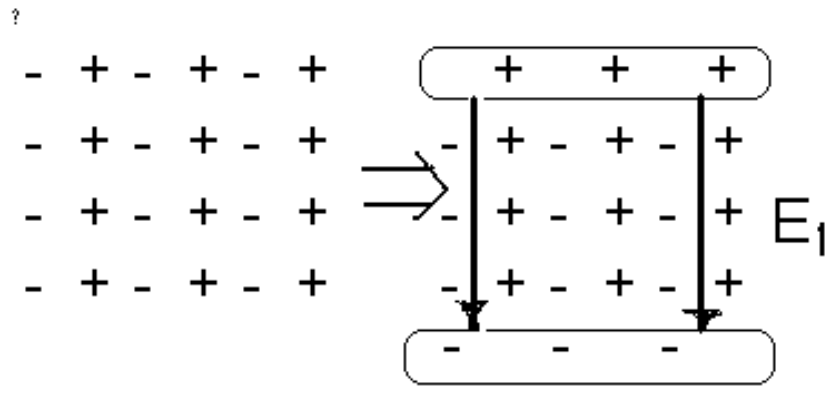

Fig. 2. Scheme of the charge distribution in the aerosol cloud at the initial moment of the cloud evolution and at a later moment of time when the electric field $E_{l}$ occurred. The large aerosol particles are negatively charged. They fall down and cause the polarization of the cloud within 1-10 min. At the initial state, the total charge of the cloud equales zero. The positive part of the charge of the cloud is formed by the small aerosol particles and the positive and negative ions.

Thus, with increasing ionization, the value of $\tau_{r}$ decreases because of the increase of $q_{i}$. On the other hand, in case of sufficiently large numbers of aerosols, the ion concentration $n$ decreases, and $\tau_{r}$ increases.

The analysis showed that the indeed main phenomenon in the radon-aerosol cloud interaction is the acceleration of the ionization process $q_{i}$. Thus the characteristic time scale of the local electric field pulses $\tau_{r}$ may decrease to $1-10 \mathrm{~min}$. The normal maxwellian relaxation time of the near-earth air equals $10-15 \mathrm{~min}$. The here proposed electro-gravitational generator has vertical dimensions of a few meters, but it might also be some tens of meters.

If the horizontal component of the electrical conductivity is diminished by one order of magnitude by the aerosols in the inner cloud, an external (with respect to the cloud) electric current occurs. This current decreases the electric field up to a value which nearly corresponds to the normal electrical conductivity in the inner part of the cloud. Thus, the value of $n / n_{o}$ equals approximately unity.

Here it should be mentioned that an increase of the dimension and the charge of the large aerosols $Q=\varepsilon_{o} \xi R$, with $\xi=0.3 \mathrm{~V}$ (Shishkin, 1954), causes an increase of the electric field $E_{l}$ proportional to $R^{3}$. Performing this estimate, it is supposed that the aerosols are enlarged by water droplets with the center of condensation lying on the initial aerosols. Correspondingly, $E_{l}$ may come up to the breakdown value at somewhat larger dimensions of the negatively charged aerosols.

In the Table 1, estimates of the characteristic time scale $\tau_{r}$ and of the maximum electric field pulses $E_{l M}$ are presented for $\alpha=10^{-7} \mathrm{~cm}^{3} \mathrm{~s}^{-1}$ and $\beta=2 \times 10^{-6} \mathrm{~cm}^{3} \mathrm{~s}^{-1}$.

From the study follows that the most interesting for the earthquake prediction parameter region is $q_{i} \approx\left(3 \times 10^{2}-3 \times 10^{4}\right) \mathrm{cm}^{-3} \mathrm{~s}^{-1}$, which corresponds to $E_{l M} \approx(0.3-6) 10^{5} \mathrm{~V} / \mathrm{m}$. The electric field pulses cause pulses of infrared emissions. The time scale of the electric field pulses is about $10 \mathrm{~min}$ or less. 
Table 1. Concentration of the positively charged aerosol particles $N_{a}^{+}$, ionization intensity $q_{i}\left(\mathrm{~cm}^{3} \mathrm{~s}^{-1}\right)$, characteristic time scale of the pulse of the local electric field $\tau_{r}$ (min), and maximum electric field $E_{l M}(\mathrm{~V} / \mathrm{m}) . \quad N_{a}^{+}=10^{4} \mathrm{~cm}^{-3}$. Bold-face numbers in the table correspond to time scales smaller than the Maxwell relaxation time of about $15 \mathrm{~min}$.

\begin{tabular}{ccccccc}
\hline$q_{i}$ & $10^{2}$ & $3 \times 10^{2}$ & $10^{3}$ & $3 \times 10^{3}$ & $10^{4}$ & $3 \times 10^{4}$ \\
\hline$\tau_{r}$ & 30 & $\mathbf{1 0}$ & $\mathbf{3}$ & $\mathbf{1}$ & $\mathbf{0 . 5 5}$ & - \\
$E_{l M}$ & $2 \times 10^{6}$ & $\mathbf{6} \times \mathbf{1 0}^{5}$ & $\mathbf{2} \times \mathbf{1 0}^{\mathbf{5}}$ & $\mathbf{6} \times \mathbf{1 0}^{\mathbf{4}}$ & $\mathbf{3} \times \mathbf{1 0}^{\mathbf{4}}$ & - \\
\hline
\end{tabular}

The process of infrared emission during the pulses of the local electric field is evidently a non-equilibrium one. It is the consequence of the electron acceleration in the electric field along a path of the order of the mean free electron path. But the heating of the atmosphere because of the infrared emission is rather small.

Further, it should be underlined that, at one and the same aerosol concentration, smaller characteristic times of the electric field pulses correspond to larger ionization intensities. With other words, if the intensity of the electric field is smaller - and the infrared emission is weaker - then the wavelength is larger. In contrary, in case that the ionization intensity will not be changed, a high aerosol concentration results into largest electric field intensities and most intense infrared emissions, as well as into longer-lasting pulses (up to tenths of minutes). The most interesting for the problem of earthquake prediction interval of infrared emissions, obviously, extends from a few $\mu \mathrm{m}$ to some hundreds of $\mu \mathrm{m}$.

\section{Discussion of experiments}

Investigating the earth by satellites, one widely uses photographs with high-resolution in the near-infrared part of the spectrum. In a series of works, stationary and non-stationary anomalies of the earth's infrared (IR) emission are discussed. The stationary anomalies are attributed to large-scale tectonic structures (e.g. deep fractures, thermal lines of water etc.). It is known that the value of the temperature difference between anomalous and background conditions may reach up to 3-4 K (Gorniy et al., 1988; Sal'man and Tronin, 1990).

Non-stationarities of anomalies are observed with respect to its dimensions and/or the time of the anomaly appearance. The existence time of the anomalies lies in the interval between two days and one month. Anomalies may extend up to some tenths of thousands of square kilometers. Some of the IR-anomalies are formed in regions with overlapping faults, and, obviously, are connected with earthquake precursors. Such anomalies may be located rather far (hundreds to thousands of kilometers) from the epicenters of the developing earthquakes. Evidently, the earthquake preparation zone has to comprise the region of IR anomalies - and the earthquake has to be genetically connected with the region of IR-anomaly along the faults.
Table 2. The same as in Table 1, but for $N_{a}^{+}=10^{5} \mathrm{~cm}^{-3}$.

\begin{tabular}{ccccccc}
\hline$q_{i}$ & $10^{2}$ & $3 \times 10^{2}$ & $10^{3}$ & $3 \times 10^{3}$ & $10^{4}$ & $3 \times 10^{4}$ \\
\hline$\tau_{r}$ & - & - & 30 & $\mathbf{1 0}$ & $\mathbf{3}$ & $\mathbf{1}$ \\
$E_{l M}$ & - & - & $2 \times 10^{6}$ & $\mathbf{6} \times \mathbf{1 0}^{\mathbf{5}}$ & $\mathbf{2} \times \mathbf{1 0}^{\mathbf{5}}$ & $\mathbf{6} \times \mathbf{1 0}^{\mathbf{4}}$ \\
\hline
\end{tabular}

IR-anomalies may be caused by an increase of the temperature of the earth's surface, which may be the consequence, for instance, by a change of the regime of the thermal water. But the temperature anomaly may be also a result of the greenhouse effect which appears above active faults because of the variation of the concentration and composition of gaseous components in the near-earth atmosphere. One also knows about a strengthening of the emanation of such gases like $\mathrm{H}_{2}, \mathrm{CO}, \mathrm{CO}_{2}, \mathrm{CH}_{4}, \mathrm{PH}_{3}$, etc. by active structures of the earth's core.

For instance, according to experiments, an increase of the $\mathrm{CO}_{2}$ or $\mathrm{CH}_{4}$ concentration in the near-earth atmosphere $\left(h \approx 2 \times 10^{3} \mathrm{~m}\right.$ ) by one order of magnitude results into an increase of the surface temperature of a few degrees (greenhouse effect). Here it has to be noticed that a growth of the concentration of such gases by one or two orders is often observed in the near-earth atmosphere during seismic activities.

Further, the growth of the surface temperature may be strengthened by meteorological factors. If cold humid air flowing to the region of thermal anomaly is heated, the steam forming the clouds is not saturated any more, and the clouds disappear. At the same time, the air temperature may also increase by the influence of the growing solar radiation flux, which, in absence of clouds, reaches the earth's surface.

Thus, indirect data on the behaviour of the thermal anomalies may be obtained studying the meteorological data above the anomaly region. Mil'kis (1986) analyzed meteorological parameters above a series of faults in Middle Asia. In the case of strong earthquakes $(M>6)$ in Middle Asia, some months - and at least some days - before the event, there were found maximum values of the solar radiation, the number of solar sparkling hours, the number of clear days, the air temperature, the solar wind, and, correspondingly, minimum values of cloudiness, the numbers of wan and misty days, precipitation, and moisture content of the air. The author proposed that the formation of meteorological anomalies is caused, above all, by thermal phenomena accompanying earthquake preparation processes.

But the above mentioned anomalies of the IR radiation possess characteristic time scales of some days and up to a maximum of one month. In the present work, pulses of IR-radiation (and of electric fields) are considered which last minutes and, at most, half an hour.

What about the repeatability of the pulses of IR radiation? Up to now, there do not exist any observations connected with earthquakes during times without thunderstorm phenomena. But observations were made before and after thunderstorm activity. 
For instance, it was found that strong oscillations of the field may begin $1-2 \mathrm{~h}$ before a thunderstorm, and their repeatability equals $0.5-1$ impulses per minute. But during the thunderstorms, the repeatability increases to 2-3 impulses per minute, and also many hours after the thunderstorm field pulses appeared (Shishkin, 1954). It is interesting to mention, that jumps of the electric field were sometimes also found during periods free of thunderstorms. The pulses of the electric field strength recurred most often in the interval of (1-5) $10^{2} \mathrm{~V} / \mathrm{m}$, and values above $10^{4} \mathrm{~V} / \mathrm{m}$ were registered only in $1 \%$ of the experiments.

In cases of thicker clouds with large vertical dimensions $L$, also the electric field $E$ is stronger. For instance, at $L=100$ $\mathrm{m}$ one has $E=500 \mathrm{~V} / \mathrm{m}$, and at $L=200 \mathrm{~m}$ it is $E=800 \mathrm{~V} / \mathrm{m}$ (Frenkel, 1949).

Interpreting the electric field pulses it was assumed, that the small positively charged water droplets move upward with the up-flowing air, but the larger, negative ice particles fall down (Frenkel, 1949; Imjanitov and Shifrin, 1962).

Besides, it is accepted that electric field pulses were found analyzing disturbances of the phase of VLF-signals $(10-20 \mathrm{kHz})$. Thus, one week before the Rudbarsk and Ratshinsk earthquakes (magnitude $M>6$ ), night-time VLFsignal disturbances with characteristic time scales of 2030 min (Gufeld et al., 1992) and 5-10 min (Gufeld, 1995) were observed. Disturbances with smaller time scales might have been existed, but they were not considered. It is believed that the observed disturbances may be interpreted within the frame of the here discussed model of the generation of local electric fields.

Further, it is well-known that reflections of waves with wavelengths of the order of meters by normal clouds are negligible. Usual reflections by thunderstorm clouds were often registered. At thunderstorm activity, during radio-location experiments, fluctuating bright points may be seen on displays. The thunderstorm discharges and the radio emissions of the lightnings are observed as lighting-up narrow indicator sectors. The geometric dimensions of the reflection region are not larger than $200 \mathrm{~km}$.

Voinov et al. (1992) studied modifications of radio signals registered before and during the Spitak earthquake $(M=6.5$, $h=10 \mathrm{~km}$ ). And on the displays of radio-stations - one week before the event, and up to three days after the event - fluctuating points of different brightness were also obtained in sectors directed towards Spitak. Most intensive effects started one day before the earthquake and ended three days after the event. The reflecting air regions existed about $10-12 \mathrm{~h}$ and were situated at altitudes of $5-30 \mathrm{~km}$. But one week before the Spitak earthquake, and up to three days after it, in the earthquake preparation zone no thunderstorm activity was obtained. The atmosphere was cloudy, and sometimes some rain was falling. It is clear that the fluctuating points on the displays were not connected with thunderstorm activity.

In accordance with the radio observations in the earthquake epicenter region, where radio-wave reflecting atmospheric layers seemed to have been formed, the density of the charged atmospheric particles equaled the minimum den- sity which occurs in thunderstorm clouds. Thus it was concluded that the layers might emit radiowaves in the meterscale. Consequently, it was demanded to continue the radio investigation of atmospheric plasma structures (Pulinets et al., 2002), as they might help to identify electro-gravitational mini-current systems and to introduce new earthquake prediction methods.

In connection with the newly proposed mechanism of the generation of local electro-gravitational mini-current systems and IR-radiation pulses, one has also to mention the hypothesis on the nature of atmospheric glowing by Grigorjev et al. (1988). According to this hypothesis, glowing of the atmosphere may occur also at electric field values weaker than the breakdown one. Grigorjev et al. related the nature of the glowing in the optical part of the spectrum to the instability of the haze droplets in the electric field. One may suggest, that in case of droplets of water aerosols, this mechanism, in connection with the here proposed model - can result into the generation of IR emissions at considered values of the electric field of $10^{4}-10^{5} \mathrm{~V} / \mathrm{m}$.

In the work (Tronin et al., 2002), basing on satellite experiments, anomalies of the IR-radiation of the earth's surface were investigated, which characterize thermal anomalies observed during earthquakes in Japane and China. The authors found positive thermal anomalies at distances of 200 to $1000 \mathrm{~km}$ from the epicenters, which were linked to systems of faults within the earth. In China, the thermal anomalies were situated at the border between mountains and valleys. The dimensions of the anomalies amounted to about $700 \mathrm{~km}$ in length and $50 \mathrm{~km}$ in wideness. The phenomena occurred 6-24 days before the earthquakes and continued even one week after the eruption. Anomalies were found for earthquakes with a magnitude $M>4.7$ and at distances of up to $1000 \mathrm{~km}$ from the epicenter. The maximum amplitudes of the anomalies amounted to $3 \mathrm{C}$. The thermal anomalies in Japan had a more difficult structure. The analysis of the Japanese data showed that the anomalies occurred 7-10 days before the earthquake, that they had much smaller dimensions, but the amplitudes grew up to $6 \mathrm{C}$.

Using nighttime land surface temperature (LST) data from Moderate Resolution Imaging Spectroradiometer (MODIS) onboard National Aeronautical Space Agency Terra satellite and comparing them with emissions from the earth's surface, also Ouzounov and Freund (2004) found correlations between the atmospheric dynamics and solid earth processes prior to the 26 January 2001 Bhuj earthquake, Gujarat in Western India $(M=7.7)$. They analyzed data covering $100 \times 100 \mathrm{~km}$. 5-6 days before the eruption, they found a strong LST increase near the earthquake epicenter (at a distance from the epicenter not larger than $200 \mathrm{~km}$ ) of 3-4 C. Besides, they observed changes of the aerosol content and atmospheric instability parameters. These changes were told to be possibly caused by modifications of the ground potential that can be the cause of ion emission from the ground and for the formation of a thin near-ground aerosol layer. It is of importance that Ouzounov and Freund (2004) concluded that the rapid LST variations could not be due to actual ground 
temperature variations caused by the heat pulse rising from within the earth. The variations seem to be caused by changing IR emissivity from the ground.

Last not least, there should be mentioned another interesting effect, which might be connected with the specific type of generation of local electric fields in the atmosphere at increasing ionization intensity. The increase of the density of the ions and charged aerosols causes a growing number of condensation centers of the water vapour and the formation of a specific type of clouds above earthquake fracture regions (Morozova, 1996, 1997). Of the cloud formation, photos may be taken by satellites and used for earthquake prediction.

Altogether, one may propose that the specific cloud formation is nothing else than a consequence of the anomalous local heating in the fracture zone before earthquakes and of the upstreaming air which contains additional ionization sources. Then, at larger altitudes where the temperature is sufficiently low so that the vapour is saturated, the processes of condensation and cloud formation start. These processes are the more effective the more condensation centers are created by the additional ionization. Besides, one may further assume that in the cloudy structures electric fields are generated and IR-emissions occur (as they appear in the near-earth atmosphere). It is of strong interest to continue in future the necessary corresponding investigations.

\section{Conclusions}

A model of the generation of pulses of local electric fields with characteristic time scales of $1-10 \mathrm{~min}$ is considered for atmospheric conditions above fracture regions of earthquakes. In the model, it is proposed that aerosols, increased ionization velocity and upstreaming air flows occur at nighttime conditions.

The pulses of local electric fields cause respective pulses of infrared emissions. Although anomalies of the infrared radiation above fault regions were repeatedly registered by satellites before earthquakes, it seems, that up to now nobody observed shorttime pulses with a duration of only 1$10 \mathrm{~min}$. Also nothing is told about the localization and measurements of non-stationary infrared emissions with scales of $1-100 \mu \mathrm{m}$. The authors think, that such non-stationary effects might be a new-type of applicable earthquake indicators.

Thus, in connection with the development of possible future earthquake prediction methods, it is of great interest to perform special earth-based and satellite observations of the night-time atmosphere in the infrared part of the spectrum (using cameras with night visibility) in seismoactive fracture regions. The investigations must include the analysis of the temporal dynamics of the infrared spectra in the region of $1-10 \mathrm{~min}$. It is desirable to perform, at the same time, measurements of the atmospheric electric field and the variations of the geomagnetic field which have also time scales of 1$10 \mathrm{~min}$. Besides one has to go ahead with radiolocation experiments.
Acknowledgements. The authors kindly thank two referees for constructive comments.

Edited by: M. Contadakis

Reviewed by: two referees

\section{References}

Al'perovich, L. S., Ponomarev, E. V., and Fedorovich, G. V.: Geophysical phenomena modeled by an explosion: a review. Izv. Acad. Nauk. SSSR. Ser. Geophys., V. 22, 816-825, 1986.

Boyarchuk, K. A., Lomonosov, A. M., Pulinets, S. A., and Hegay, V. V.: Variability of the Earth's atmospheric electric field and ionaerosol kinetics in the troposphere, Studia Geophysica et Geodaetica, 42, 197-206, 1998.

Elster I. and Geitel, H.: Zur Influenztheorie der Niederschlagselektrizität, Phys. Zeitschr., 14, 1287-1296, 1913.

Frenkel, Ya. I.: Theory of atmospheric electricity phenomena, GITTL, M.-L., 1949.

Geitel, H.: Zur Frage nach dem Ursprunge der Niederschlagselektrizität, Phys. Zeitschr., 17, 455-464, 1916.

Gorniy, V. I., Sal'man, A. G., Tronin, A. A., and Shilin, B. V.: Escaping the earth infrared emission - indicator of seismic activity, Doclady Academii Nauk SSSR, 301, 67-69, 1988.

Grigor'jev, A. I., Gershenzon, A. I., and Gokhberg, M. B.: On the nature of atmospheric glowing connected with earthquakes, Doclady Academii Nauk SSSR, 300, 1087-1090, 1988.

Gufel'd, I. L., Roshnoi, A. A., Tjumenzev, S. N., and Sherstjuk, S. B.: Disturbances of radiowave fields before the Rudbarsk and Ratshinsk earthquakes, Izvestija Academii Nauk, Fizika Zemli, 3, 102-106, 1992.

Gufel'd, I. L.: Radiowave precursors of core earthquakes, United Institute for Physics of the Earth of the Russian Academy of Sciences, referat to the $\mathrm{PhD}$ thesis, Moscow, 1995.

Heinke, J., Koch, H., and Martinelli, G.: $\mathrm{CO}_{2}$ and radon measurements in the Vostland (Germany) - a contribution to earthquake prediction research, Geophys. Res. Lett., 22, 744-749, 1995.

Imjanitov, I. M. and Shifrin, K. S.: Modern investigation of atmospheric electricity, Uspekhi Fizisheskikh Nauk, 76, 593-642, 1962.

Kamra, A. K.: Measurements of the electrical properties of dust storm, J. Geophys. Res., 77, 5856-5869, 1972.

Kolokolov, L. E. and Shalagina, N. A.: Effects of explosion of Karymsky volcano in the bottom area of ionosphere in "Researches of geomagnetism and problems of aeronomy in high latiitudes", Academy of Science of USSR, Far-Eastern Scientific Center, Magadan, (in Russian), 76-79, 1978.

Kondrat'jev, K. Ja. and Poznjakov, D. V.: Aerosol models of the atmosphere, Nauka, Moscow, 1981.

Mil'kis, M. P.: Meteorological precursors of strong earthquakes, Fizika Zemli, 3, 36-47, 1986.

Morozova, L. I.: Peculiarities of the occurrence of lithosphereatmosphere connections during strong Asian earthquakes, Fizika Zemli, 5, 63-68, 1996.

Morozova, L. I.: Dynamics of cloudy anomalies above fracture regions during natural and anthropogenically caused seismic activities, Fizika Zemli, 9, 94-96, 1997.

Ouzounov D. and Freud F.: Mid-infrared emission prior to strong earthquakes analyzed by remote sensing data, Adv. Space Res., 33, 268-273, 2004. 
Poljakov, S. V., Rappoport, V. O., and Trakhtengertz, V. Ju.: On the generation of electric waves in the upper atmosphere, Geomagnetism and Aeronomy, 30, 869-871, 1990.

Pulinets, S. A. and Boyarchuk, K. A.: Ionospheric precursors of earthquakes, Springer, 2005.

Pulinets, S. A., Boyarchuk, K. A., Hegai, V. V., and Karelin, A. V.: Conception and model of seismo-ionospheremagnetosphere coupling, Seismo Electromagnetics, in: Lithosphere-Atmosphere-Ionosphere Coupling, edited by: Hayakawa, M. and Molchanov, O. A., Tokyo, Terrapub, 353-361, 2002.

Pulinets, S. A., Boyarchuk, K. A., Hegai, V. V., Kim, V. P., and Lomonosov, A. M.: Quasielectrostatical model of atmospherethermosphere-ionosphere coupling, Adv. Space Res., 26, 12091218, 2000.

Sal'man, A. G. and Tronin, A. A.: Variations of the flux of infrared emission of the earth in seismo-active regions of Middle Asia, Izvesta AN SSSR, Fizika Zemli, 3, 67-69, 1990.

Schumann, T. E.: On Elster and Geitel's theory of the electrification of rain drops, Phys. Rev., 26, 105-110, 1925.

Shishkin, N. S.: Cloud, precipitation and thunderstorm electricity, GITTL, Moscow, 1954.

Smirnov, V. V.: Ionization in the troposphere, Gidrometeoizdat, St. Petersburg, 1992.

Sorokin, V. M. and Jashtshenko, A. K.: Disturbances of the quasistationary electric field in the atmosphere above seismo-active regions, Chemical Physics, 19, 71-80, 2000.
Trakhtengerts, V. Yu.: On the nature of electric elements in the thunderstorm cloud, Doklady AN SSSR, 308, 3, 584-586, 1989.

Trakhtengerts, V. Yu.: Electric field generation in atmospheric convective cells, J. Atmos. Terr. Phys., 54, 217-222, 1992.

Trakhtengerts, V. Yu.: The generation of electric fields by aerosol particle flow in the middle atmosphere, J. Atmos. Terr. Phys., 56, 337-342, 1994.

Tronin, A. A., Hayakawa, M., and Molchanov, O. A.: Thermal IR satellite data application for earthquake research in Japan and China, J. Geodynamics, 33, 519-534, 2002.

Vershinin, E. F., Buzevitch, A. V., Yumoto, K., Saito, K., and Tanaka, Y.: Correlation of seismic activity with electromagnetic emissions and variations in Kamchatka region, in: Atmospheric and Ionospheric Phenomena Associated with Earthquakes, edited by: Hayakawa, M., TERRAPUB, Tokyo, 513517, 1999.

Voinov, V. V., Gufel'd, I. L., Kruglikova, V. V. et al.: Effects in the ionosphere and atmosphere before the Spitak earthquake on 7 December 1988, Izvestia AN Fizika Zemli, No. 3, 1992.

Virk, H. S. and Singh, B.: Radon recording of Uttarkashi earthquake, Geophys. Res. Lett., 21, 737-740, 1994.

Wilson, C. T. R.: Some thunderstorm problems, Journal of The Franklin Institute Devoted to Science and the Mechanic Arts, 208, 1243-1, 1-12, 1929. 